\title{
The use of artificial neural networks for analyzing the sensitivity of a retention tank
}

\author{
Kamil Pochwat ${ }^{1, *}$ \\ ${ }^{1}$ Rzeszow University of Technology, Department of Infrastructure and Water Management, \\ al. Powstańców Warszawy 6, 35-959 Rzeszów, Poland
}

\begin{abstract}
Designing retention facilities is a complex engineering process that requires the collection of the detailed hydrological data of a catchment and hydraulic sewerage system. The acquired data are necessary to prepare a model of the retention tank in appropriate software for hydrodynamic modelling. The article shows the results of tests concerning the analysis of the sensitivity of a sewerage model of a rainwater retention tank which may be implemented in this software. The results of tests allowed determining the impact of the individual hydraulic characteristics of the catchment and the sewerage system on the required retention capacity of a tank. A planned analysis is performed based on artificial neural networks and the required data are acquired by hydrodynamic simulations in SWMM 5.1.
\end{abstract}

\section{Introduction}

The increasing sealing of urban areas results in larger volumes of waste rainwater directed to sewerage systems $[1,2,3]$. Its effect is a higher flow rate of wastewater in sewerage and water courses $[4,5]$. Their quality deteriorates as well, which is caused by high organic and inorganic pollutions [6]. This results in the need to continuously modernize the system and adapt it to the new hydraulic flow conditions. In such cases, it is beneficial to perform a financial analysis that is helpful in choosing a solution to this problem $[7,8,9,10,11]$. Very often its result indicates the necessity to use devices that periodically store the excess of rainwater, among which the most important are retention tanks.

A serious issue related to the use of retention facilities is properly determining their required retention capacity. Currently, there are many procedures used for designing retention tanks that allow obtaining very reliable results provided that hydrodynamic modelling software is used. However, these require a complex model of catchment and sewerage system that are characterized by a high number of hydraulic and hydrological characteristics. This issue has been discussed in the works [12], where the author uses the Hellwig's information capacity indicator method and showed a low importance of roughness coefficients of a catchment and a sewerage system in the design of retention tanks. A similar task has been done by Skotnicki and Sowiński [13] who showed the variability of catchment discharge hydrographs depending on the values of these characteristics.

*Corresponding author: kp@prz.edu.pl 


\section{Aim of the research}

The goal of the tests is to analyze the impact of the hydraulic and hydrological characteristics of a catchment and sewerage system in the dimensioning of a required tank's retention capacity. The results may be helpful for designers of retention facilities to eliminate from among the high number of hydraulic characteristics of a catchment and sewerage system, those that are less important from the viewpoint of dimensioning of retention tanks and determine those that should be considered, particularly during the design process. This will reduce the number of calculations needed to determine the required capacity.

\section{Object of research}

The object of tests is a single-chamber retention tank for the hydraulic relief of a sewerage network. The tank operated as a flow tank which is shown in Figure 1.

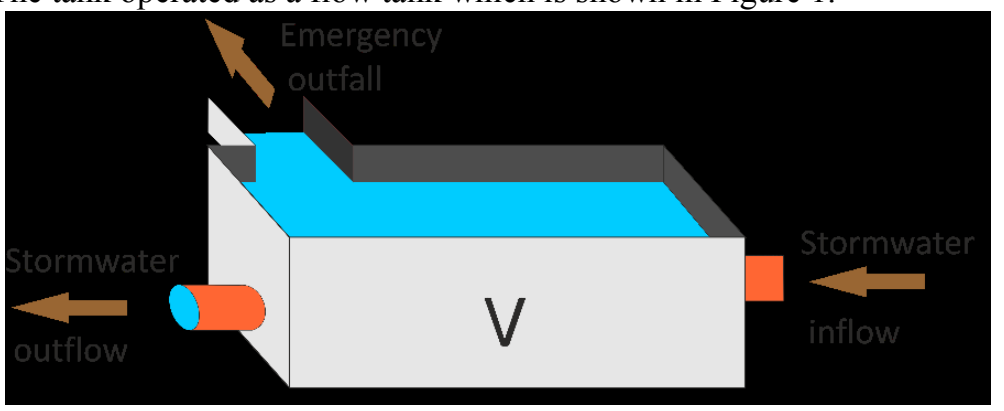

Fig. 1. Retention tank diagram.

The basic design characteristics is a retention capacity which is conditioned by the hydraulic and hydrological characteristics of the catchment and the rainfall selected depending on the assumed degree of hydraulic safety.

According to the assumed methodology, the quality specification of model characteristics has been provided, which consisted of classification into three basic groups:

- input characteristics (independent variables)

- output characteristics (dependent variable);

- constant characteristics.

A sewerage model of a retention tank that includes input variables (independent characteristics) as well as output value (dependent variable), which is the required retention capacity and the constants are shown in Figure 2.

The range of individual independent variables to be analyzed is shown in Table 1. The group of characteristics included:

- Wastewater level to sewer diameter $(h k / D)$,

- Maximum theoretical wastewater level in a tank $h s$. 


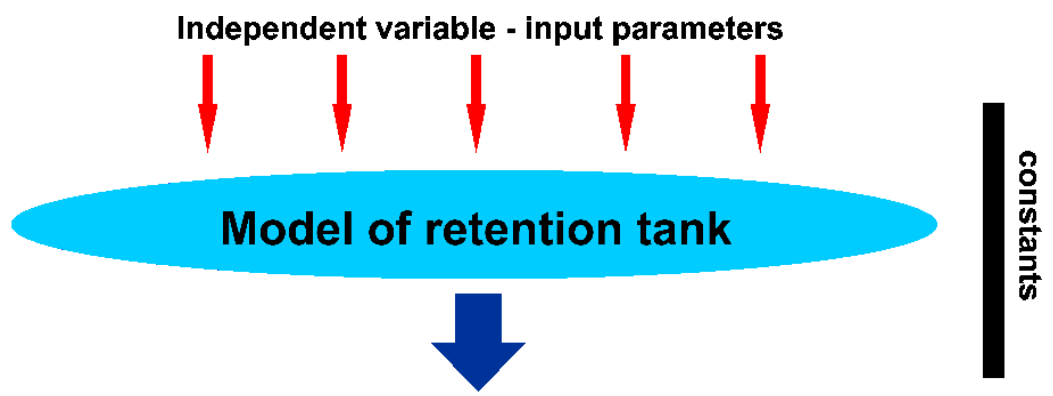

Dependent variable - output parameter

Fig. 2. Quality model of the tested element.

The first stage of tests was to acquire the data for analysis which were received by simulations made with SWMM hydrodynamic modelling software. These calculations were to determine the required retention capacity of tank $V$ (output characteristics, dependent variable) in different configurations of the sewerage system.

Table 1. The parameters characterizing the object of study.

\begin{tabular}{|c|c|c|c|}
\hline Independent variable & Description & Minimum & Maximum \\
\hline Flow reduction coefficient, $\boldsymbol{\beta}$ & $\begin{array}{c}\text { Ratio of maximum volumetric flux of } \\
\text { incoming wastewater QA and volumetric } \\
\text { discharge flux QB }\end{array}$ & 0,2 & 0,9 \\
\hline Sewer roughness coefficient, $\boldsymbol{n}_{\boldsymbol{k}}$ & Roughness of wastewater line & $0.008 \mathrm{~s} / \mathrm{m}^{1 / 3}$ & $0.013 \mathrm{~s} / \mathrm{m}^{1 / 3}$ \\
\hline Catchment roughness coefficient, $\boldsymbol{n}_{\boldsymbol{z}}$ & Catchment surface roughness & $0.013 \mathrm{~s} / \mathrm{m}^{1 / 3}$ & $0.04 \mathrm{~s} / \mathrm{m}^{1 / 3}$ \\
\hline Sewer length, $\boldsymbol{L}_{\boldsymbol{k}}$ & $\begin{array}{c}\text { Network length from initial node to } \\
\text { retention tank section }\end{array}$ & $100 \mathrm{~m}$ & $2000 \mathrm{~m}$ \\
\hline Sewer gradient, $\boldsymbol{\%}$ & Sewer bottom inclination against level & $1 \%$ o & $10 \%$ o \\
\hline Catchment gradient, $\boldsymbol{\%} z$ & Plane inclination against level & $1 \%$ o & $10 \%$ o \\
\hline Catchment width & \multicolumn{2}{|c|}{ Surface runoff width } & $2 \cdot L_{k}$ \\
\hline
\end{tabular}

A literature review [14] allowed determining that with an increased drainage surface $F$, the required retention capacity of tank $V$ is higher. As a result, the tests did not cover its impact on the retention capacity of tank $V$ and only covered the catchment of 5 ha.

\section{Methodology}

Tests to determine the impact of analyzed hydraulic characteristics on the capacity of a retention tank were made for a dataset consisting of the results from simulations of the operation of different sewerage systems. The analysis covered how the capacity of a retention tank changes when varying one input value with the same values of other characteristics. An example of some of the analyzed data is shown in Table 2. A total of 565 system configurations were analyzed.

The sensitivity analysis of a retention tank was conducted using the neural networks. Statistica software was used to generate the analysis. The acquired data were input into the program environment and in the creator for artificial neural networks; the settings were defined in the division of data into:

test data $-70 \%$ of all data

learning data $-15 \%$ of all data 
validation data - $15 \%$ of all data.

The neural networks obtained with a creator were put into a selection where one network characterized by the lowest error and highest match value was chosen.

Table 2. The sample of parameters used in the analysis.

\begin{tabular}{|c|c|c|c|c|c|c|c|}
\hline 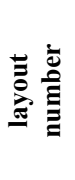 & 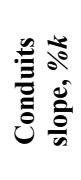 & 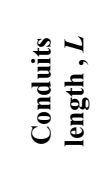 & 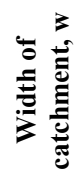 & 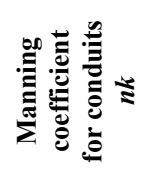 & 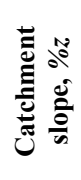 & 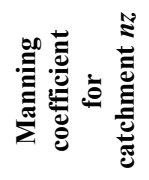 & 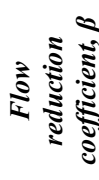 \\
\hline & $\%$ & $\mathrm{~m}$ & $\mathrm{~m}$ & $\mathrm{~s} / \mathrm{m} 1 / 3$ & $\%$ & $\mathrm{~s} / \mathrm{m} 1 / 3$ & - \\
\hline 1 & 1.00 & 250.00 & 100 & 0.01 & 5.00 & 0.02 & 0.2 \\
\hline 2 & 2.00 & 250.00 & 100 & 0.01 & 5.00 & 0.02 & 0.2 \\
\hline 3 & 3.00 & 250.00 & 100 & 0.01 & 5.00 & 0.02 & 0.2 \\
\hline 4 & 4.00 & 250.00 & 100 & 0.01 & 5.00 & 0.02 & 0.2 \\
\hline 5 & 5.00 & 250.00 & 100 & 0.01 & 5.00 & 0.02 & 0.2 \\
\hline 6 & 6.00 & 250.00 & 100 & 0.01 & 5.00 & 0.02 & 0.2 \\
\hline 7 & 7.00 & 250.00 & 100 & 0.01 & 5.00 & 0.02 & 0.2 \\
\hline 8 & 8.00 & 250.00 & 100 & 0.01 & 5.00 & 0.02 & 0.2 \\
\hline 9 & 9.00 & 250.00 & 100 & 0.01 & 5.00 & 0.02 & 0.2 \\
\hline 10 & 10.00 & 250.00 & 100 & 0.01 & 5.00 & 0.02 & 0.2 \\
\hline 11 & 3.00 & 100.00 & 100 & 0.01 & 5.00 & 0.02 & 0.2 \\
\hline 12 & 3.00 & 150.00 & 100 & 0.01 & 5.00 & 0.02 & 0.2 \\
\hline 13 & 3.00 & 200.00 & 100 & 0.01 & 5.00 & 0.02 & 0.2 \\
\hline 14 & 3.00 & 250.00 & 100 & 0.01 & 5.00 & 0.02 & 0.2 \\
\hline 15 & 3.00 & 350.00 & 100 & 0.01 & 5.00 & 0.02 & 0.2 \\
\hline 16 & 3.00 & 500.00 & 100 & 0.01 & 5.00 & 0.02 & 0.2 \\
\hline 17 & 3.00 & 750.00 & 100 & 0.01 & 5.00 & 0.02 & 0.2 \\
\hline 18 & 3.00 & 1000.00 & 100 & 0.01 & 5.00 & 0.02 & 0.2 \\
\hline 19 & 3.00 & 1500.00 & 100 & 0.01 & 5.00 & 0.02 & 0.2 \\
\hline 20 & 3.00 & 2000.00 & 100 & 0.01 & 5.00 & 0.02 & 0.2 \\
\hline$\ldots$ & $\ldots$ & $\ldots$ & $\ldots$ & $\ldots$ & $\ldots$ & $\ldots$ & $\ldots$ \\
\hline
\end{tabular}

\section{Result of research}

The MLP neural network model (Multi-Layered Perceptron) with architecture 7-12-1 was suggested to predict the results of the capacity of a retention tank $V$. The network had the lowest learning errors $(0.997664)$, testing errors $(0.996860)$ and validation errors $(0.997003)$ among other networks offered by the program.

The principle of operation of this network consists in calculating the weighted average from the input values by each neuron. The result itself is calculated with a transition function and led to the output. As an activation function in a hidden layer and an output layer, an exponential function was assumed and the error function was determined with the sum of squares method. 
The neural network whose architecture is shown in Figure 3 is characterized by seven neurons in an input layer, twelve neurons in a hidden layer and one neuron in an output layer.

Manning coefficient for conduit, $n k$

Manning coefficient for catchment, $n z$

Wastewater flow reduction factor, $\beta$

Lenght of conduits, $m$

Conduits slope, \%o

Catchments slope, $\%$

Width of catchments, \%o

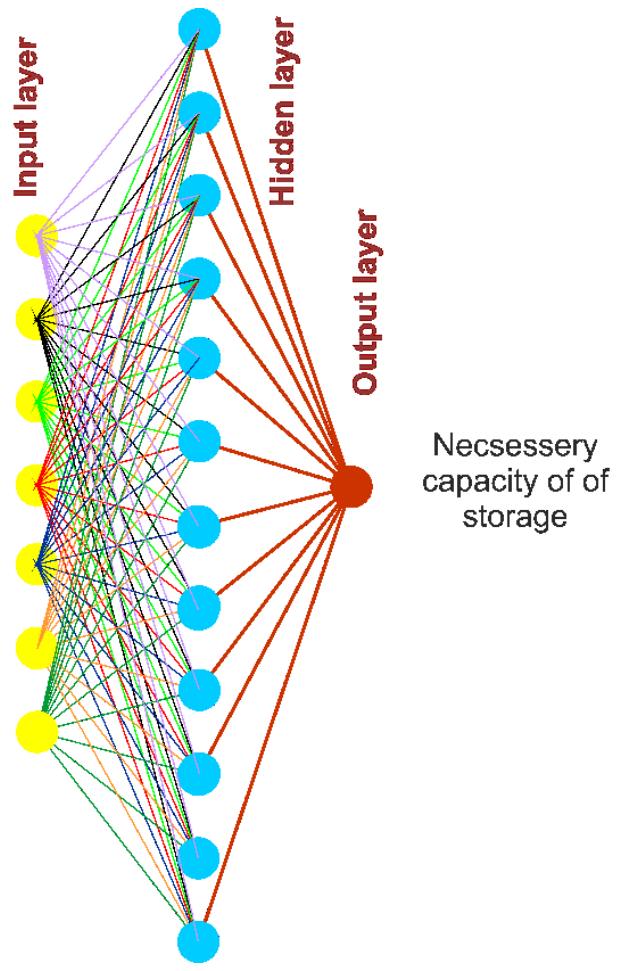

Fig. 3. Diagram of an artificial neural network for a retention tank model.

Based on the results of simulation tests and results calculated using neural networks, it can be said that the described model of an artificial neural network has a high accuracy. This is shown in Fig. 4 which compares the expected values as results of achieved required retention capacity from computer simulations and values obtained with a developed model of artificial neural network.

Based on the developed neural network mode, a global sensitivity analysis was performed to indicate which characteristics mostly impact the required retention capacity of tank $V$. The result of it are the values assigned to each characteristics and the higher the value, the greater is the impact on a dependent variable. The results are shown as a bar diagram in Figure 5. 


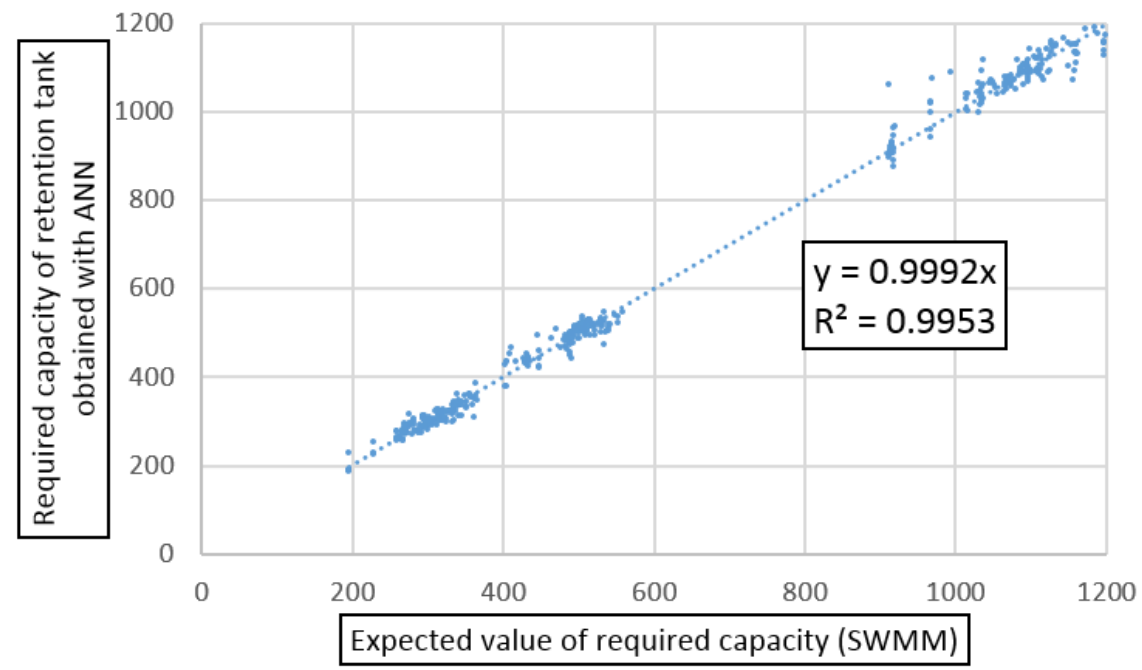

Fig. 4. Analysis of linear regression between experimental data and SSN calculation.

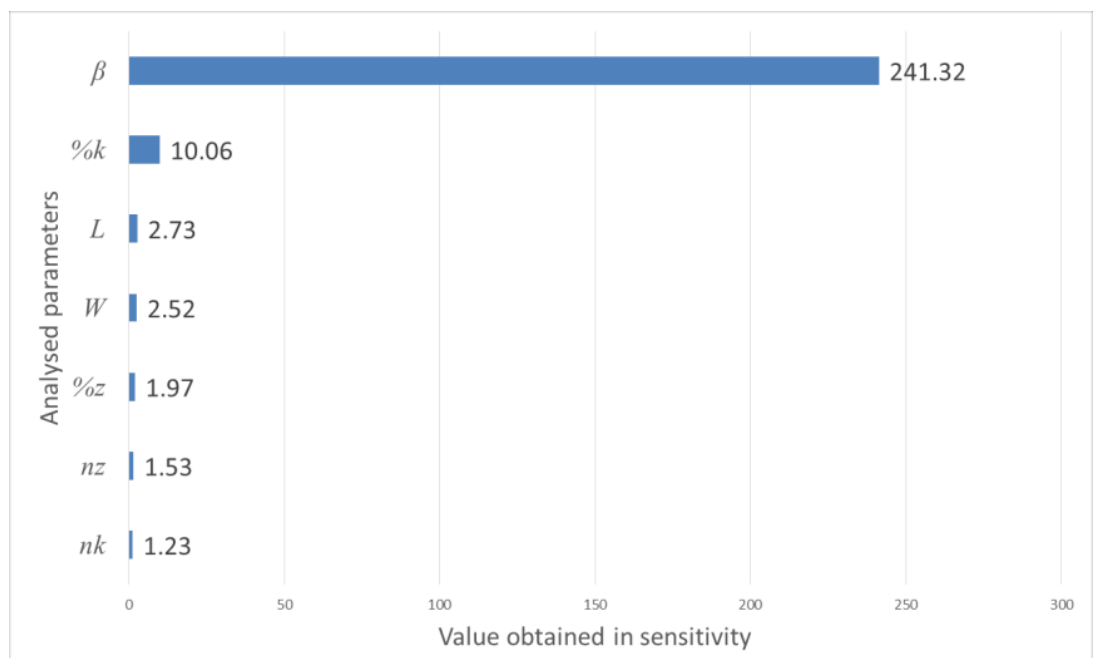

Fig. 5. Global sensitivity analysis $(n k-$ sewer roughness coefficient, $n z$ - catchment roughness coefficient, $\% z$ - catchment gradient, $W$ - catchment width, $L-$ sewer length, $\% k$ - sewer gradient $B-$ flow reduction coefficient).

The data implies that the greatest impact on the required retention capacity of retention tank $V$ is shown by the wastewater flow reduction coefficient $\beta$. This value was 241.32. Another high value (10.06) was shown by the sewer line gradient $\% k$. Other characteristics have a small impact on a dependent variable (values below 3 ).

However, it should be noted that there is a high discrepancy among the top results of the wastewater flow reduction coefficient $\beta$ and sewer gradient $\% \mathrm{k}$. Therefore, further analysis were made for constant values of $\beta$ coefficients equal to $0.2,0.5$ and 0.8 . For this purpose, individual neural networks were developed for the flow reduction coefficients $\beta$.

Further tests led to the development of three artificial neural networks (SSN) whose typical characteristics are compared in Table 3. 
Table 3. Characteristic parameters of obtained artificial neural network for the defined flow reduction coefficient $\beta$.

\begin{tabular}{|c|c|c|c|}
\hline & \multicolumn{3}{|c|}{ Flow reduction coefficient } \\
\hline & 0.2 & 0.5 & 0.8 \\
\hline $\begin{array}{l}\text { Network } \\
\text { architecture }\end{array}$ & MLP 6-11-1 & MLP 6-7-1 & MLP 6-6-1 \\
\hline Quality (learning) & 0.963341 & 0.968000 & 0.948031 \\
\hline Quality (testing) & 0.881908 & 0.952681 & 0.924667 \\
\hline Quality (validation) & 0.921822 & 0.770830 & 0.915865 \\
\hline Activation function & Exponential & Exponential & $\begin{array}{c}\text { Hyperbolic } \\
\text { tangent }\end{array}$ \\
\hline $\begin{array}{l}\text { Output activation } \\
\text { function }\end{array}$ & $\begin{array}{c}\text { Hyperbolic } \\
\text { tangent }\end{array}$ & Hyperbolic tangent & Linear \\
\hline
\end{tabular}

The created artificial neural networks were used for a global sensitivity analysis of a retention tank at a constant reduction coefficient $\beta$. Results of this analysis are shown in Figure 6.

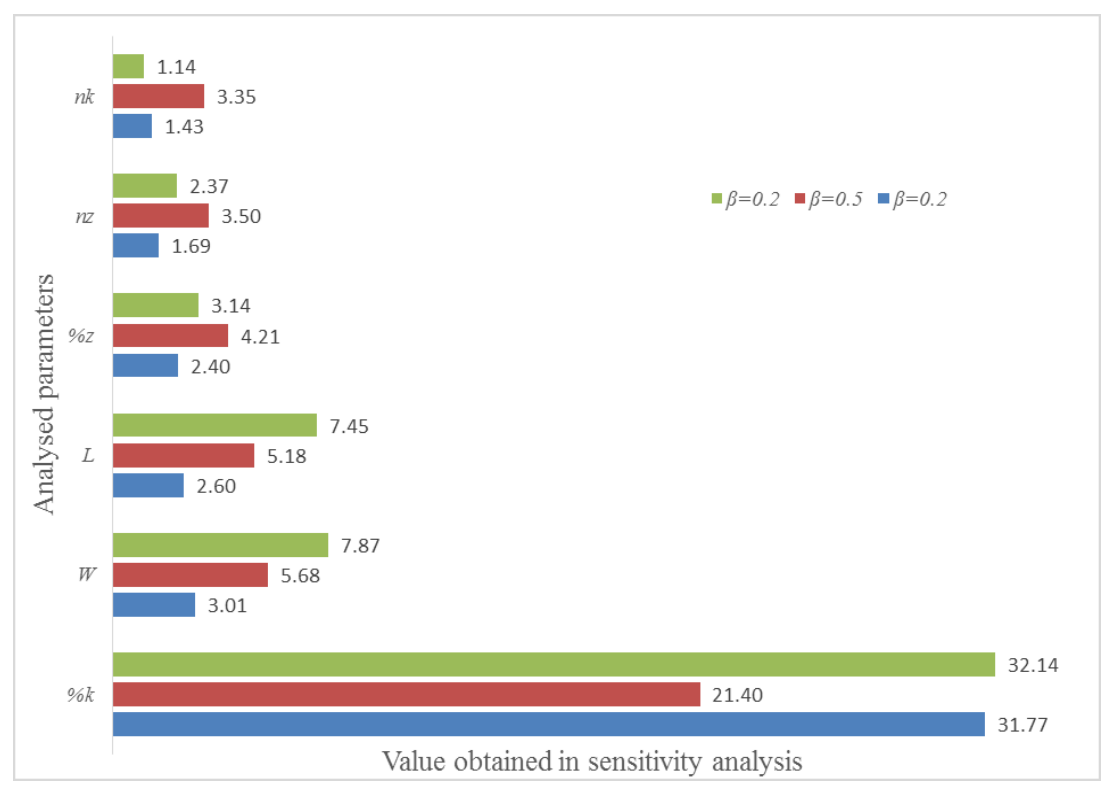

Fig. 6. Global sensitivity analysis for coefficients $\beta 0.2,0.5,0.8$ ( $n k-$ sewer roughness coefficient, $n z-$ catchment roughness coefficient, $\% z$ - catchment gradient, $W$ - catchment width, $L$ - sewer length, $\% k$ - sewer gradient $B$ - flow reduction coefficient).

Considering the results separately for each value of the wastewater flow reduction coefficient $\beta$, it can be concluded that a hierarchy of importance was preserved for the analyzed characteristics, which was achieved in the first stage of tests. The analysis confirmed that the greatest values (impact) was shown by sewer gradient $\% k$, then the runoff width $W$, sewer length $L$, catchment gradient \%z; and the lowest importance can be assigned to roughness coefficients of the catchment $n z$ and the sewers $n k$.

On the other hand, an analysis of the whole range of flow reduction coefficient $\beta$ showed that the importance of other characteristics $(\% z, L, W, n k, n z)$ depends on its value. It does not apply to the sewer gradient which at this stage has always, regardless of $\beta$, had the highest values. 
The analysis at the first and the second stage allowed establishing that the highest impact was shown by $\beta$ and sewer gradient $\% k$; while the lowest impact was shown by roughness coefficients for the catchment $n z$ and the sewer system $n k$.

The results are coherent with the work of Pochwat [12] in respect of a small impact of $n z$ and $n k$ coefficients on the required retention tank capacity. The tests [12] were done with the Hellwig's information capacity indicator method and the cohesion of results in this respect confirms the rightness of the conclusions and relevance of using both methods. This rightness is also confirmed in the work of Skotnicki [13], where the author states that the change of said values affects the discharge hydrographs but the differences are small.

\section{Conclusions}

The global sensitivity analysis for a model of a sewer retention tank with the use of artificial neural networks allowed determining the catchment and sewer system input characteristics which have the greatest and the lowest impact on the required retention tank $V$ capacity. The tests also confirmed the usefulness of artificial neural networks in analyzing the sensitivity of retention elements.

The tests allowed drawing the following practical and cognitive conclusions:

- Flow reduction coefficient $\beta$ and sewer system gradient $\% \mathrm{k}$ have the greatest impact on the required retention tank $\mathrm{V}$ capacity;

- Manning's roughness coefficient for the sewer $n k$ and for the catchment $n z$ can be considered insignificant to determine the required retention capacity of $\operatorname{tank} V$;

- Flow reduction coefficient $\beta$ affects the hierarchy of importance of characteristics nz, $n k$, $W, L, \% z$ impact on the required retention capacity of tank $V$.

\section{References}

1. A. Stec, D. Słyś, Ecol. Chem. Eng. S 20, 381-396 (2013)

2. K. Pochwat, E3S Web Conf. 17, 00075 (2017)

3. M. Starzec, J. Dziopak, Underground Infrastructure of Urban Areas 4, 181-191 (2018)

4. K. Pochwat, D. Słyś, S. Kordana, J. Hydrol. 549, 501-511 (2017)

5. M. Starzec, J. Dziopak, D. Słyś, Underground Infrastructure of Urban Areas 4, 193-200 (2018)

6. M. Kida, S. Ziembowicz, P. Koszelnik, Sep. Purif. Technol. 192, 457-464 (2018)

7. D. Słyś, A. Stec, Ecol. Chem. Eng. S 21, 623-635 (2014)

8. S. Kordana, E3S Web Conf. 17, 00042 (2017)

9. D. Słyś, S. Kordana, Energ. Buildings 71, 1-11 (2014)

10. A. Stec, A. Mazur, D. Słyś, E3S Web. Conf. 22, 00168 (2017)

11. A. Mazur, D. Słyś, E3S Web. Conf. 17, 00058 (2017)

12. K. Pochwat, D. Słyś, JCEEA 63 (2/II), 371-382 (2016)

13. M. Skotnicki, M. Sowiński, JCEEA 63 (2/II), 413-428 (2016)

14. J. Dziopak, Analiza teoretyczna i modelowanie wielokomorowych zbiorników kanalizacyjnych (wyd. Politechniki Krakowskiej, Kraków, 1992) 